\title{
EDITORIAL
}

\section{Utopias e ingenuidades da educação ambiental?}

Entre visões ingênuas e utópicas de educação ambiental, tanto nas formuladas políticas nacionais como nas práticas de educação ambiental, pode-se notar um lento movimento para transformações. Sobre uma generalização da Educação Ambiental (EA) feita por Kawasaki et al. (2009) e Carvalho (2001) há indícios de mudanças em relação ao seu caráter marcadamente instrumental, a uma visão pragmática e imediatista das práticas educativas, o que, para os autores, revela certa ingenuidade no enfrentamento da complexa temática ambiental e a uma visão caracterizada como "ilusão ou otimismo pedagógico".

Um percurso dessas transformações é possível a partir de pesquisas de tendências ou estados do conhecimento. Parte-se de Amaral (2001), que analisa as relações entre EA e o ensino de ciências nas décadas de 1970, 80 e 90. Depois, temos a pesquisa de Fracalanza et al. (2008) sobre o estado da arte da EA no Brasil, baseada em 807 dissertações e teses produzidas entre 1981 e 2004. Reigota (2007) apresenta os resultados de pesquisa sobre o estado da arte em EA no Brasil. Em seu doutorado, Lorenzetti (2008) discute os estilos de pensamento em EA a partir de dissertações e teses produzidas de 1981 a 2003, ou seja, uma base de dados semelhante a de Fracalanza et al. (2008). Em seguida, com o dossiê sobre EA no periódico Educação em Revista da Universidade Federal de Minas Gerais (UFMG), temos os trabalhos de González-Gaudiano e Lorenzetti (2009), que traçam tendências da EA na América Latina, com maior detalhe para Brasil e México. Nesse mesmo dossiê, temos também o artigo de Rink e Megid Neto (2009), no qual analisam os trabalhos de pesquisa publicados nos Anais dos Encontros de Pesquisa em Educação Ambiental (EPEA), realizados no período de 2001 a 2007 (quatro primeiros encontros). Ainda há o trabalho de Kawasaki et al. (2009), que faz análises dos trabalhos de EA apresentados nos Encontros Nacionais de Pesquisa em Educação em Ciências (ENPEC).

Amaral (2001) apresenta um cenário de controvérsias e de diversidade de concepções da educação ambiental em suas relações com o ensino de ciências, mostrando um campo em emergência. Os trabalhos de Fracalanza et al. (2008), González-Gaudiano e Lorenzetti (2009), e Lorenzetti (2008) discutem alguns aspectos dos percursos da EA no Brasil, que em muito se assemelham às ideias de De Alba (2007) trazidos à tona no texto de González-Gaudiano e Lorenzetti sobre a EA no México. A EA continua sendo um campo emergente e em processo de constituição, contando com estruturação incipiente, sobretudo pela carência de centralidade definida, que se expressa na fraca fundamentação teórica, essencialmente de índole empírico- 
descritiva, revelado na falta de quadros próprios de referência que são importados do campo do ensino de ciências, da educação, das ciências ambientais e das humanidades. Daí que, para muitos, a EA possui caráter marginal tanto no campo educativo quanto no ambiental. Nessa fase, pode-se afirmar que seu objeto de estudo ainda é uma projeção intradisciplinar das disciplinas mães, isto é, como se EA fosse uma parte aplicada dessas ciências. Percurso muito parecido com a fase emergente do ensino de ciências traçado por Cachapuz (2015). Nessa fase, há uma confluência complexa e conflituosa de pesquisadores que provêm de diversas disciplinas, os quais são constituidores do campo da EA, fazendo parte desse processo configuracional dialético de forças internas e externas que buscam orientar a EA em direção à interdisciplinaridade, à multirreferencialidade, à intercientificidade e à interprofissionalidade, ou seja, sua identidade não está ainda desenhada. A EA com estatuto autônomo de área interdisciplinar e objetos de estudos próprios ainda está em construção. Não há pistas sólidas de que, por exemplo, a epistemologia ambiental de Leff (2001) cumpra esse papel em uma fase seguinte na história da EA no Brasil.

No ambiente escolar as práticas de EA (e, consequentemente, as pesquisas dela decorrentes) têm sido realizadas privilegiando sua articulação com o currículo do Ensino de Ciências e/ou Biologia e Geografia; temáticas que apresentam nítidos vínculos com a Ecologia e as relações entre sociedade e ambiente surgem com maior ênfase sob a ótica da Geografia; discussões de problemas ambientais com forte conotação técnica relacionada a concepções biológicas (LIMA, 1999; SORRENTINO, 1997, entre outros).

A pesquisa de Lorenzetti (2008) evidencia que as políticas públicas e os cursos de formação inicial e continuada não estão contribuindo para o estabelecimento da consciência da complicação e complexidade e a consequente transformação do estilo de pensamento ecológico em EA, tão predominante no contexto da Educação Básica no Brasil. Aspecto corroborado por Rink e Megid Neto (2009), que explicitam desafios para a formação inicial e continuada, na medida que as pesquisas não mostram indícios de que o educador ambiental está superando práticas tradicionais, clássicas e conservadoras de ensino, que não contribuem para a formação da consciência ambiental dos alunos. Segundo os autores, para que isso ocorra deve ser delineado um novo perfil didático e pedagógico do educador, para que se considerem as implicações políticas, ideológicas, econômicas e éticas de seu fazer educativo. Colocam a necessidade de trabalhos que se dediquem a investigar de que forma a EA tem estado presente na trajetória de formação dos educadores ambientais, ou seja, como capacitar um docente para a inserção de uma EA crítica e transformadora do contexto social dos alunos?

Rink e Megid Neto (2009) observam que há grande preocupação dos pesquisadores em identificar, mapear e cartografar as características e concepções de indivíduos sobre algum conceito ou aspecto da EA. Por outro lado, destacam que há falta de trabalhos que discutam questões políticas na área. Esse mesmo aspecto vem ocorrendo também no ensino de ciências no Brasil, assunto já observado e levantado como preocupação nos ENPEC.

Provavelmente por causa de sua origem, pois, segundo Carvalho (2001), a experiência brasileira de EA não nasceu no campo educativo, mas parece ser um fenômeno cuja gênese e cujo desenvolvimento estariam mais ligados aos movimentos ecológicos e ao debate ambientalista, um ponto a destacar é que a EA tem tido, talvez, mais sucesso do que o ensino de ciências em apresentar como problemática para a formação cidadã e florestã a dualidade entre desenvolvimento econômico e preservação ambiental e, assim, suscitando de várias formas as discussões sobre as formas de produção do capitalismo e as possibilidades de uma concepção de planeta sustentável.

Esse debate põe na mesa para discussão as ideias da vanguarda modernista que buscava ultrapassar a concepção burguesa vulgar de progresso e mantinha a crença nas possibilidades de 
uma dimensão liberadora trazida pela tecnologia e pelo desenvolvimento científico (JAMESON, 2006). Do movimento crítico a essas ideias surgiu o enfoque Ciência-Tecnologia-Sociedade (CTS) no ensino de ciências, que hoje, devido às questões postas pela crise socioambiental viu acentuada a dimensão e a designação cada vez maior de enfoque Ciência-Tecnologia-Sociedade -Ambiente (CTSA). Porém, esse enfoque (CTS ou CTSA) no ensino de ciências ainda tem sua abrangência bastante limitada nas práticas escolares. Dentre várias causas, provavelmente, uma delas é a própria rigidez curricular com poucas práticas formativas que não são disciplinares nos cursos de licenciaturas. Os professores formados numa cultura disciplinar encontram outra estrutura disciplinarizada rígida, hierarquizada e autoritária que são, de modo geral, os sistemas de ensino (federal, estadual e municipal). Desse modo, tem havido um casamento que mantém as disciplinas como centro da vida escolar, dificultando sobremaneira práticas inovadoras como as de CTSA. A EA, de origem mais recente e proposta nos currículos como tema transversal e em menor escala como interdisciplinar, vem se configurando como uma modalidade educacional com aspectos pedagógico e epistemológico voltados à integração entre contexto, interdisciplinaridade, flexibilidade curricular na resolução de problemas locais e na sua relação com o global.

O mapeamento das tendências temáticas em EA nos trabalhos apresentados nas reuniões da Associação Nacional de Pós-graduação e Pequisa em Educação (ANPED), mais especificamente no GT22 dos anos de 2003 a 2007, feito por Pato, Sá e Catalão (2009) corrobora com as mudanças nas práticas de EA, pois os autores afirmam que ao longo dos anos vai havendo o distanciamento da visão conservacionista e o surgimento da visão crítica da EA, predominante nos últimos dois anos. Com isso, apontam que a abordagem socioambiental, que reconhece aspectos políticos e culturais como constitutivos de uma nova postura epistemológica, crítica e implicada, é notável no conjunto dos trabalhos analisados. Possivelmente, dessas características e futuras práticas, a EA adentrará em sua fase de consolidação como área interdisciplinar com objeto(s) próprio(s) de estudo e estatuto identitário autônomo.

\section{Maurício Compiani}

Universidade Estadual de Campinas (Unicamp), Faculdade de Educação, Campinas, SP, Brasil. e-mail: compiani@unicamp.br

\section{Referências}

AMARAL, I. A. Educação ambiental e ensino de ciências: uma história de controvérsias. Pro-posições, Campinas, v. 12, n. 1, p. 73-93, 2001.

CACHAPUZ, A. F. Pesquisa em educação em ciências: uma história de sucesso. In: SANTOS, R. R.; BONITO, J. Pensar e construir a universidade no século XXI. Boa Vista: EDUFRR, 2015. p. 151-174.

CARVALHO, L. M. A educação ambiental e a formação de professores. In: BRASIL. Ministério da Educação. Panorama da educação ambiental no ensino fundamental. Brasília, 2001. p. 55-65. 
DE ALBA, A. Investigación en educación ambiental en América Latina y el Caribe: doce tesis sobre su constitución. In: GONZÁLEZ-GAUDIANO, E. (Ed.). La educación frente al desafío ambiental global: una visión latinoamericana. México: Plaza y Valdés-Crefal, 2007. p. 277-287.

FRACALANZA, H. et al. A educação ambiental no Brasil: panorama inicial da produção acadêmica. Ciências em Foco, Campinas, v. 1, n. 1, p. 1-14, 2008.

GONZÁLEZ-GAUDIANO, E.; LORENZETTI, L. Investigação em educação ambiental na América Latina: mapeando tendências. Educação em Revista, Belo Horizonte, v. 25, n. 3, p. 191-211, 2009.

KAWASAKI, C. S. et al. A pesquisa em educação ambiental nos ENPECs: contextos educacionais e focos temáticos. In: ENCONTRO NACIONAL DE PESQUISADORES EM EDUCAÇÃO EM CIÊNCIAS, 7., 2009, Florianópolis. Anais... Florianópolis: UFSC, 2009.

JAMESON, F. Espaço e imagem: teorias do pós-moderno e outros ensaios. Rio de Janeiro: Ed. UFRJ, 2006.

LIMA, G. F. C. Questão ambiental e educação: contribuições para o debate. Ambiente \& Sociedade, Campinas, v. 2, n. 5, p. 135-153, 1999.

LEFF, E. Epistemologia ambiental. São Paulo: Cortez, 2001.

LORENZETTT, L. Estilos de pensamento em educação ambiental: uma análise a partir das dissertações e teses. Tese (Doutorado em Educação Científica e Tecnológica) Universidade Federal de Santa Catarina, Florianópolis, 2008.

PATO, C.; SÁ, L. M.; CATALÃO, V. L. Mapeamento de tendências na produção acadêmica sobre educação ambiental. Educação em Revista, Belo Horizonte, v. 25, n. 3, p. 213-233, 2009.

REIGOTA, M. O estado da arte da pesquisa em educação ambiental no Brasil. Pesquisa em Educação Ambiental, Rio Claro, v. 2, n. 1, p. 33-65, 2007.

RINK, J.; MEGID NETO, J. Tendências dos artigos apresentados nos encontros de pesquisa em educação ambiental (EPEA). Educação em Revista, Belo Horizonte, v. 25, n. 3, p. 235-263, 2009.

SORRENTINO, M. Vinte anos de Tbilisi, cinco da Rio-92: a educação ambiental no Brasil. Debates Socioambientais, São Paulo, v. 2, n. 7, p. 3-5, 1997. 